\title{
Laser nanothermolysis of human leukemia cells using functionalized plasmonic nanoparticles
}

Anton V. Liopo ${ }^{1}$, André Conjusteau ${ }^{1}$, Marina Konopleva ${ }^{2}$, Michael Andreeff ${ }^{2}$ and Alexander A. Oraevsky ${ }^{1}$

${ }^{1}$ TomoWave Laboratories, 6550 Mapleridge St., Suite 124, Houston TX 77081, USA

${ }^{2}$ Department of Leukemia and Department of Stem Cell Transplantation and Cellular Therapy, The University of Texas MD Anderson Cancer Center, 1515 Holcombe Blvd., Houston, TX 77030, USA

* Corresponding author: al@tomowave (Anton V. Liopo)

Tel/fax.: (+1) 713-270-5393/713-270-5392

\begin{abstract}
In the present work, we present the use of gold nanorods as plasmonic nanoparticles for selective photothermal therapy of human acute (HL-60) and chronicle (K-562) leukemia cells using a near-infrared laser. We improved a published methodology of gold nanorods conjugation to generate high yields of narrow band gold nanorods with an optical absorption centered at $760 \mathrm{~nm}$. The manufactured nanorods were pegylated and conjugated with monoclonal antibody to become non-toxic as biocompatible nanothermolysis agent. Gold nanorods are synthesized and conjugated to CD33 monoclonal antibody. After pegylation, or conjugation with CD33 antibody, gold nanorods were non-toxic to acute and chronic leukemia cells. Our modified gold nanorod CD33 conjugates shown high level of accumulation for both leukemia cell lines, and successful used for nanothermolysis of human leukemia cells in vitro. Each sample was illuminated with 1 or 3 laser shots as for low and for high laser fluence. The radiation was provided by a Quanta Systems q-switched titanium sapphire laser, and the system was designed for maximum sample coverage using non-focused illumination. HL-60 and K-562 cells were treated for 45 min with gold nanorods CD33 conjugated, or with pegylated gold nanorods. The effect of pulsed-laser nanothermolysis for acute and chronic leukemia cells were investigated with cell counting for number of living cells, percentage of cell death and functional parameters such as damage of cell membrane and metabolic activity. Gold nanorods CD33 conjugates significantly increase cell damage for low fluence laser and completely destroyed cancer cells after 3 pulses for low fluence (acute leukemia) and for high fluence laser as for HL-60 (acute) and for K-562 (chronicle) leukemia cells.
\end{abstract}

Keywords: Laser Nanothermolysis, Gold Nanorods, Conjugates, Monoclonal Antibody, Human Leukemia Cells

Citation: Anton V Liopo, et al. Laser nanothermolysis of human leukemia cells using functionalized plasmonic nanoparticles. Nano Biomed. Eng. 2012, 4(2), 66-75.DOI: 10.5101/nbe.v4i2.p66-75.

\section{Introduction}

Gold nanoparticles have attracted significant interest as a novel platform for nanobiotechnology and biomedicine because of convenient surface bioconjugation with molecular probes and remarkable optical properties related with the localized plasmon resonance [1-4]. Gold nanoparticles of various shapes have promising biomedical applications in the fields of drug delivery, biomedical imaging, and chemical sensing [5-7]. Plasmonic nanoparticles have shown promise in hyperthermic cancer therapy, both in vitro and in vivo [8]. The use of structurally modified gold nanoparticles is less toxic to normal tissue during delivery, and at the molecular level, could traverse biologic barriers and preferentially accumulate in cancer cells $[4,9,10]$.
Nanoparticles can be targeted to the tumor and subjected to laser irradiation from an external source, leading to the selective localization of hyperthermic treatment [11].

One type of gold nanoparticle with a strong tunable plasmon resonance in the near-infrared spectral range is the gold nanorod (GNR) [2]. Consequently, gold nanorods have been employed in diagnostics [12] therapeuticdelivery systems [13], imaging [14], sensing [15], and responsive advanced materials assemblies [8]. Properties such as biocompatibility, ease of functionalization, and near infrared optical imaging make gold nanorods promising in novel theranostic platforms [16]. GNRs were also used as optoacoustic (OA) contrast agents for 
quantitative flow analysis in biological tissues [17] and to investigate the kinetics of drug delivery compounds [18]. GNR stabilized with CTAB show strong cytotoxicity and usually require PEG-modification by adding PEG-SH in the CTAB solution[19]. Reasons for PEGylation (i.e. the covalent attachment of PEG) of surfaces nanoparticles are numerous and include shielding of antigenic and immunogenic epitopes, shielding receptor-mediated uptake by the reticuloendothelial system, and preventing recognition and degradation by proteolytic enzymes for biopolymers and aggregation of GNR into cells [20, 21]. GNR can absorb light about one thousand times more strongly than an equivalent volume of an organic dye $[2,22]$. Demonstrations of photothermal cancer therapy using gold nanorods as a photothermal converter have also been reported by several groups [7, 8, 23]. Targeting gold nanorods to a specific site is both a critical aspect of bioimaging using gold nanorods as a contrast agent, and for achieving efficient photothermal therapy without side effects especially after intravenous injection [23-26]. The standard for conjugating gold nanoparticles to antibodies using covalent bonding was published by several research groups $[1,8,27,28]$. However, the conjugation processes are in need of improvement. Most protocols are hard to adapt to large-scale manufacturing of highly concentrated conjugates with strong affinity toward factors such as biochemical and physiological conditions of the cells and organs of the body [29].

In these studies, we adopted a published methodology of GNR conjugations to get high yields of narrow band GNR with an optical absorption centered at $760 \mathrm{~nm}$. The manufactured nanorods were pegylated and conjugated with monoclonal antibody (mAb) to become nontoxic as biocompatible OA nanothermolysis agent. We characterized the conjugation efficiency of the GNRs $\mathrm{mAb}$ by comparing the efficiency of antibody binding of the GNRs before and after pegylation. We demonstrated a new application of PEG-coated gold nanorod monoclonal antibody conjugates in preclinical research through photothermal therapy involving acute and chronic human leukemia cells. Differentiation between the two types of cells was observed in viability studies following treatment with GNR conjugates. Further differences were observed through irradiation with low number of laser pulses after specified targeting: the number of receptors is different for both types of cells, and therefore affects GNR conjugate uptake. We have demonstrated successful implementation of laser nanothermolysis of human leukemia cells using functionalized plasmonic nanoparticles.

\section{Materials and Methods}

\section{Fabrication, conjugation and characterization of gold nanorods}

We present below the details of a GNR fabrication protocol adapted from previously reported methodology $[26,30,31]$. The scheme of synthesis and conjugation of
GNR is presented in Fig. 1. The base procedure is tailored to the needs of the specific experiments presented in this paper. It allows high-yield fabrication of a narrow size distribution of rods with a $760 \mathrm{~nm}$ plasmon resonance. In a typical procedure, $0.250 \mathrm{~mL}$ of an aqueous 0.01 $\mathrm{M}$ solution of $\mathrm{HAuCl}_{4} \cdot 3 \mathrm{H}_{2} \mathrm{O}$ was added to $7.5 \mathrm{~mL}$ of a $0.1 \mathrm{M} \mathrm{CTAB}$ solution in a test tube (15 $\mathrm{ml}$ glass tube). Then, $0.600 \mathrm{~mL}$ of an aqueous $0.01 \mathrm{M}$ ice-cold $\mathrm{NaBH} 4$ solution was added all at once. This seed solution was used 2-4 hours after its preparation. In the next step of the fabrication, exact proportions of $4.75 \mathrm{~mL}$ of $0.10 \mathrm{M}$ CTAB, $0.200 \mathrm{~mL}$ of $0.01 \mathrm{M} \mathrm{HAuCl}_{4} \cdot 3 \mathrm{H}_{2} \mathrm{O}$, and 0.030 $\mathrm{mL}$ of $0.01 \mathrm{M} \mathrm{AgNO}_{3}$ solutions were added one at a time in the preceding order, then gently mixed by inversion. The solution at this stage appeared bright brown-yellow in color. Then $0.032 \mathrm{~mL}$ of $0.10 \mathrm{M}$ Ascorbic Acid was added. The solution became colorless upon addition and mixing of Ascorbic Acid. Ten minutes were allowed for the reaction to fully proceed before adding the required quantity of seed solution. The reaction mixture was gently mixed for 10 seconds and left undisturbed for 1-3 hours. Then, the solution was left under thermostatic conditions for 24 hours at the temperature of $30 \mathrm{o}$ C. GNR with different aspect ratios can be manufactured through changes of concentration of $\mathrm{AgNO}_{3}$, ascorbic acid, or seed solution $[5,12,30]$. GNR with plasmon resonance to the red of $850 \mathrm{~nm}$ were fabricated using a binary surfactant mixture of benzyldimethylhexadecylammoniumchlori de (BDAC) and CTAB as described in the literature [32]. GNR of different aspect ratio were prepared and presented in Figure 2. Before covalent binding with polyethylene glycol (PEG), or conjugation with monoclonal antibody CD33, the GNR were centrifuged at low speed (4000 $\mathrm{rpm}, 10 \mathrm{~min}$ ) for separation of unwanted aggregates like platelets and stars. The GNR-CTAB complex is now ready for further modification.

For pegylation $[14,19,28]$, the GNR-CTAB solution was centrifuged at $14000 \mathrm{~g}$ for 10 minutes, the supernatant was removed, and the pellet was resuspended in DI water to reduce the residual CTAB concentration to $0.01 \mathrm{M}$. Then, $0.1 \mathrm{ml}$ of $2 \mathrm{mM}$ potassium carbonate $\left(\mathrm{K}_{2} \mathrm{CO}_{3}\right)$ was added to $1 \mathrm{ml}$ of aqueous GNR solution and $0.1 \mathrm{ml}$ of 0.1 mM mPEG-Thiol-5000 (Laysan Bio Inc., Arab, AL). The resulting mixture was kept on a rocking platform at room temperature overnight. Excess $\mathrm{mPEG}$ thiol was removed from solution by two rounds of centrifugation prior to final resuspension in PBS ( $\mathrm{pH}$ 7.4).

For conjugation with monoclonal antibody, the procedure replaces CTAB as described in the literature $[26,27]$ on the surface of GNR with 16-Mercaptohexadecanoic acid (MHDA, Sigma) for activation, monoclonal antibody (in this study, CD33), and mPEG-Thiol-5000 (PEG).

For this, one $\mathrm{ml}$ of synthesized GNR in CTAB was centrifuged twice in a $1.5 \mathrm{~mL}$ Eppendorf tube at 14000 RPM for 10 minutes and resuspended in one $\mathrm{mL}$ of 
Milli-Q water (MQW) to a concentration of $1 \mathrm{nM}$. Then, $10 \mu \mathrm{L}$ of $5 \mathrm{mM}$ MHDA in ethanol was added to the GNR and the solution was sonicated for 30 minutes at $50{ }^{\circ} \mathrm{C}$ to prevent aggregation. The solution was centrifuged at 12000 RPM for 10 minutes, the supernatant was removed, and the pellet was resuspended in MQW. $10 \mu \mathrm{l}$ EDC (1-ethyl-3-[3-imethylaminopropyl] carbodiimide hydrochloride, Pierce) and sulfo-NHS (N-hydroxysulfosuccinimide, Pierce) was added from stock solution in MES (2-(4-Morpholino) ethane Sulfonic Acid, Sigma) buffer in $10 \mathrm{mM}$ and $0.4 \mathrm{mM}$ concentrations, respectively. The mixture was sonicated for 30 minutes at room temperature to produce activated GNR (GNR that are capable of binding to the amine side chain of proteins). Commercial, purified, mAb CD33 (BD Pharmingen) was added to a final concentration of 25 $50 \mu \mathrm{g} / \mathrm{mL}$ to $1 \mathrm{ml}$ of $1 \mathrm{nM}$ activated GNR. The mixture was sonicated at room temperature (RT) for 1 hour and then left on a rocking platform overnight. Following the removal of excess CD33, $10 \mu$ of PEG-Thiol $(1 \mathrm{mM})$ was added to $1 \mathrm{~mL}$ of GNR-CD33 conjugates and the mixture was incubated at room temperature for $12 \mathrm{~h}$.

This protocol for conjugation of GNR has been further modified at TomoWave Laboratories to improve reliability and increase the stability of the conjugates, at a lower financial cost, in comparison with previously published protocols [26-28]. It only differs by the order of surface modification steps. As before the GNR-CTAB complex was resuspended in one $\mathrm{ml}$ of MQW. The GNR solution was then added to a mixture of MHDA and PEG (in molar ratio 5:1) and the pegylation was performed overnight as presented above. The solution was centrifuged at 12000 RPM for 10 minutes, the supernatant was removed, and the pellet was resuspended in MQW. $10 \mu \mathrm{l}$ of a mixture of EDC and sulfo-NHS were added from stock solution in MES buffer in $10 \mathrm{mM}$ and $0.4 \mathrm{mM}$ concentrations, respectively. The resulting solution was gently agitated for $30 \mathrm{~min}$ at RT. The solution was again centrifuged at 12000 RPM for 10 minutes, the supernatant was removed and commercial, purified, mAb CD33 (BD Pharmingen) was added to a final concentration of $25-50 \mu \mathrm{g} / \mathrm{mL}$ to $1 \mathrm{ml}$ of $1 \mathrm{nM}$ activated GNR. The mixture was incubated at RT for 1 hour and then left on a rocking platform overnight.

The final step for all methods of conjugation was centrifugation of the final solution at $12000 \mathrm{~g}$ for 10 minutes. Then, the supernatant was removed and the pellet was resuspended in PBS ( $\mathrm{pH} 7.4)$ to the required concentration according to the molar extinction of our GNR $(3.85 \times 109 \mathrm{M}-1 \mathrm{~cm}-1)$ [26] and confirmed by optical density measurement by Beckman 530 or Thermo Scientific Evolution 201 spectrophotometer.

A comparative study was performed in order to measure the number of CD33 molecules on the surface of GNR for both conjugation methods. After confirming suitability, the novel order of conjugation was used for all experiments related to the characterization of physicchemical properties of GNR and their conjugates, as well as all in-vitro experiments involving GNR-CD33.

The zeta-potential of GNR before and after formation of different conjugates was measured with a high performance particle sizer (Malvern Instruments Ltd., Southborough, MA, USA) at $25^{\circ} \mathrm{C}$, and ten 20 -second runs were performed for each sample. Zeta-potential is a measure of both particle stability and adhesion. More negative or positive values of zeta-potential are associated with more stable particle solution, because repulsion between the particles reduces the particle aggregation [33].

A measure of total and bound protein (mAb CD33) was performed with the Pierce Micro BCA ${ }^{\text {TM }}$ Protein Assay Reagent Kit (Pierce). Concentration of CD33 was measured before, and after addition of GNR-activated solution: it is dependent upon either level of monoclonal antibody, or incubation time. As negative control we used only solutions of antibody without GNR. The determination was performed through measurement of absorbance at or near $562 \mathrm{~nm}$. It is important to note that the ratio of absorbance at $562 \mathrm{~nm}$ (proteins relative to BSA) has a coefficient of variation of only around $10 \%$ [26].

\section{Cell culture, viability and proliferation assays}

Two human cells lines were used. These are K-562 (chronic leukemia, CML) and HL-60 (acute leukemia), both grown at $37.0^{\circ} \mathrm{C}, 95 \%$ air and $5 \%$ carbon dioxide, with renewal of the medium every 2-3 days. Cell lines were purchased from ATCC (Manassas, VA, USA) or obtained from Leukemia Department the University of Texas M.D. Anderson Cancer Center, Houston, TX, USA and were grown in $10 \mathrm{ml}$ flasks in RPMI-1640 medium with $10 \%$ fetal bovine serum (Hyclone).

The working concentration of GNR was determined through monitoring the toxic effect of GNR-PEG conjugates incubation with acute and chronicle leukemia cells. Dose dependence effects of GNR-PEG on percentage of cell death (staining with Trypan Blue) for acute (H-60) and chronic (K-562) human leukemia cells after administration for $24 \mathrm{~h}, \mathrm{n}=4, \mathrm{M} \pm \mathrm{SD}$ strongly demonstrated that below a concentration of $1 \mathrm{nM}$, significant damages to cells cannot be observed. From this result, all our experiments were performed with concentration of GNR conjugates ranging between 0.5 and $0.25 \mathrm{nM}$.

Cell viability after incubation of leukemia cells with GNR conjugates was determined using a kit for the detection of LDH (Roche), and measuring MTT assay (Roche) after laser application.

Cell proliferation was determined by examining the conversion of MTT to a purple formazan product by metabolically active cells using a standard kit (Roche). Absorbance of the LDH and MTT products was measured 
on a plate spectrophotometer (Bio-Tek Instruments, Inc.). The second technique to assess cell viability is based on trypan blue (Sigma) dye exclusion. The cells were incubated 5 min with $0.4 \%$ trypan blue, and counted as a percentage of stained cells to total number of cells.

GNR optical visualization was performed through the use of a silver staining kit (BBI International, UK) according to manufacturer instruction, after fixation of cells with formaldehyde $(2.5 \%)$ and glutaraldehyde $(1.5 \%)$.

Cell survival following GNR conjugates incubations in concentration of $500 \mathrm{pM}$ or $3 \times 10^{11} \mathrm{GNR} / \mathrm{ml}$ was monitored. Both types of leukemia cells were seeded into a 48 -well plate at a density of $0.5 \times 10^{6}$ cells $/ \mathrm{ml}$ in $0.5 \mathrm{ml}$ of media per well. Then, the cells were collected (around $50 \mu \mathrm{l}$ was reserved for trypan blue staining) and slowly centrifuged $(500 \times \mathrm{g})$. The supernatant was used for LDH assay; the pellet was resuspended in essential media and the suspension was put into 96 wells plate for MTT assay. The toxic effects of GNR-CTAB, GNR-PEG, GNR conjugates, and unbound CD33 mAb (25 nM) were quantified through use of Trypan blue staining, LDH release, and MTT assay. Number of living cells, percentage of cell death, LDH release, ratio between LDH release and number of living cells after administration of different GNR conjugates were measured (48 h, 500 pM or $\left.3 \times 10^{11} \mathrm{GNR} / \mathrm{ml}, \mathrm{n}=4, \mathrm{M} \pm \mathrm{SD}\right)$.

\section{Laser Thermotherapy}

Acute (HL-60) and chronic (K-562) leukemia cells were pretreated for 45 min with GNR-CD33 conjugates or GNR-PEG in concentration of 250 pM (OD 1.0). Both types of GNR conjugate modifications as well as control cells were added to small non-hermetically closed Eppendorf tube at the required final concentration. After centrifugation and removal of supernatant, the cells were resuspended in a small volume of PBS ( $\mathrm{pH} 7.4)$ and put in a custom-made cuvette $(25 \mu \mathrm{l})$, ready for irradiation. The laser is mildly focused, and the focal spot is located above the top of the cuvette for maximum coverage of the number of cells being irradiated: we ensure the beam size matches the diameter of the bottom of the cuvette. After laser treatment, the cells were resuspended, and stained with Trypan blue in order to count the number of dead and living cells, measured LDH release and MTT as described above. We analyzed the total number of cells, number of living cells, number of dead cells and percentage of cell death, $\mathrm{LDH}$ release, ratio of $\mathrm{LDH}$ release to number of living cells, metabolic active cells (MTT assay) and ratio between LDH release and MTT. All experimental data presented is analyzed from 3 independent measurements as mean $\pm \mathrm{SD}$

The visualization of GNR-PEG and GNR CD33 conjugates the cells (HL-60 and K-562) were stained with a SS Kit (BBI International, UK) according to manufacturer's instructions[34].

\section{Laser system}

We used a Quanta Systems Nd:YAG second harmonic (532 nm) pumped titanium-sapphire (Ti:Sapph) laser emitting at a center wavelength of $755 \mathrm{~nm}$. Through a system of polarizing optics, the output energy can be varied continuously up to about $100 \mathrm{~mJ}$ per $10 \mathrm{~ns}$ pulses. The laser is engineered to operate at a repetition rate of $10 \mathrm{~Hz}$. In order to adequately control the experimentation conditions (energy deposited per sample), a custommade switch box was devised to allow for singlepulse operation. Our experimental setup is presented in Fig. 3. We show the cuvette holder for pulsedlaser nanothermolysis of human leukemia cells. For the purpose of this experiment, the simple system was assembled mostly from off-the-shelf parts available from Thorlabs: it replaces the laser's articulated arm commonly used for light delivery, and mounts directly onto the laser system. It features optical tubes and a plano-convex (focusing) lens mounted in an X-Y adjustable holder. The curvature of the lens is chosen such that the focal spot is located above the top of the assembly, where a cage is located. It is thus possible to carefully locate the focus high enough above the sample such that the beam diameter at the bottom of the cuvette corresponds exactly to the diameter needed to achieve the desired fluence. In the present case, we have used both a low and a high fluence setting, with values respectively of 0.6 and $1.1 \mathrm{~J} /$ $\mathrm{cm} 2$. A full width at half maximum diameter of $1.7 \mathrm{~mm}$ at $100 \mathrm{~mJ}$ output energy allows achieving the high fluence requirement. Furthermore, it ensures the bottom of the cuvette is well illuminated by the laser beam. Doing so implies the volume of the laser beam traveling through the cuvette does match that of the cuvette itself and maximizes illumination of the sample. Unfortunately, because of the Gaussian nature of the illumination beam profile, a fraction of the sample is experiencing weaker illumination, and our nanothermolysis yields are lower than optimal. The sample holders, or cuvettes, were assembled in-house. They are made of $4 \mathrm{~mm}$ sections of Pyrex tube with $3 \mathrm{~mm}$ inside diameter affixed onto a microscope slide with cyanoacrylate adhesive.

\section{Results and Discussion}

Fig. 4 presents the UV-VIS spectra of GNR after low speed centrifugation of GNR-CTAB: Pellet containing mostly platelets and stars, and other non-rodlike particles, after pegylation (GNR-PEG), and after conjugation with monoclonal antibody (GNR-CD33). Normalization was performed to even out the intensity of the absorption maximum at the transverse plasmon resonance. We demonstrate constant absorption line width as well as insignificant red shift of the plasmon resonance maximum, thereby indicating the success of the conjugation.

The intensity of the spectral features in the UV VIS at $\mathrm{OD}=1$ corresponds to a concentration of GNR in solution around $250 \mathrm{nM}$, or $1.55 \times 10^{11} \mathrm{GNR} / \mathrm{ml}$. In this project we 
http://nanobe.org

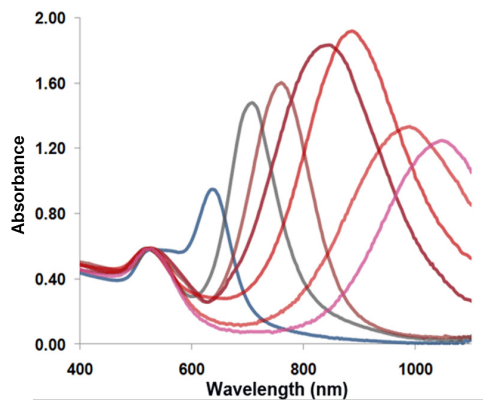

$\begin{array}{lllllll}645 & \mathbf{7 1 0} & \mathbf{7 6 0} & \mathbf{8 5 0} & 890 & 990 & 1050\end{array}$

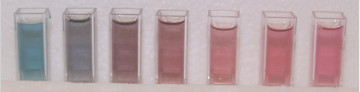

Fig. 2 Near-infrared absorption spectra of GNR with gradually increasing aspect ratio

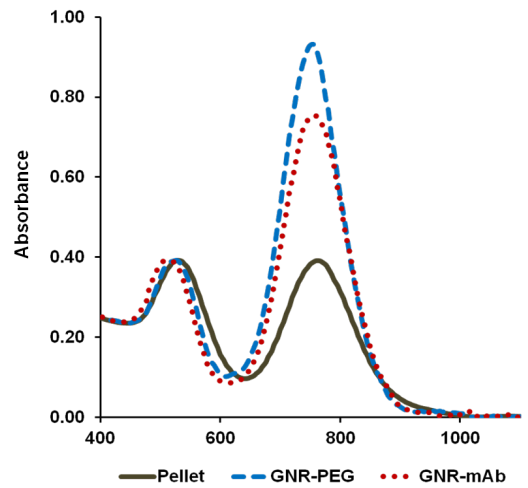

Fig. 4 Normalized absorption spectra of GNR: after low speed centrifugation of GNR-CTAB (Pellet), after PEGylation of GNR (GNRPEG), and after GNR CD33 conjugation and pegylation (GNR mAb)
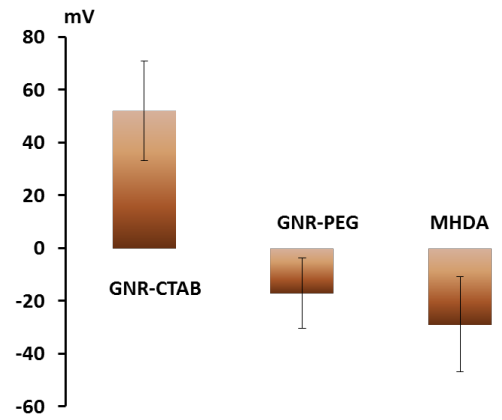

GNR-CD33 GNR-PEG-CD33

Fig. 5 Zeta-Potential for Different GNR Surface Ligands: Confirmation of Surface Chemistry Modification
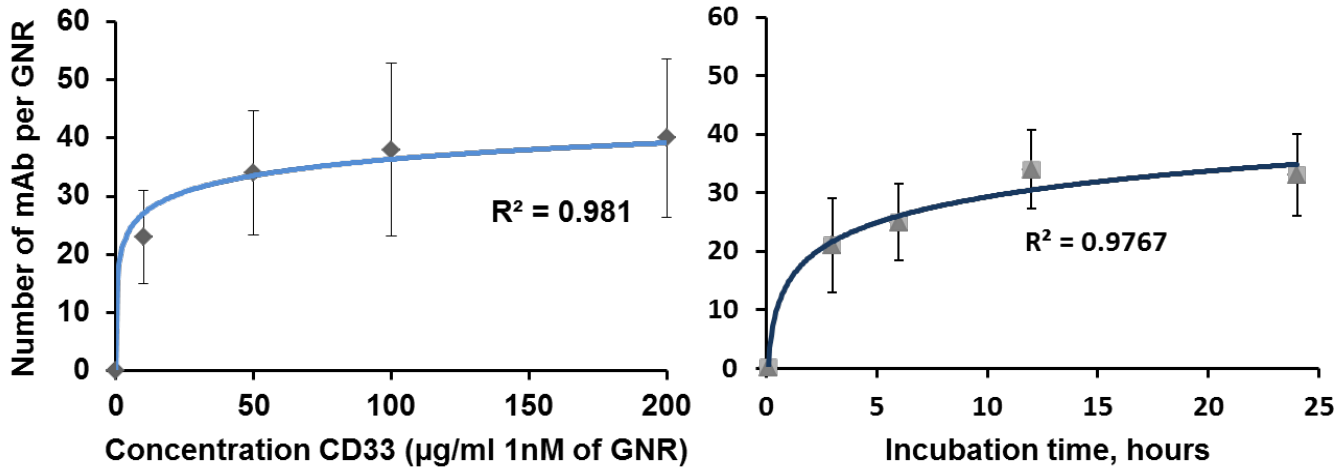

Fig. 6 Binding of CD33 on the surface of GNR: Concentration (left) and incubation time (right) effects 
then proceeded to determine the extinction coefficient of our GNR. Gold has a face-centered cubic (fcc) unit cell with 4 atoms per unit. The density of the solid is 19.32 $\mathrm{g} / \mathrm{cm}^{3}$. From this, each $\mathrm{nm}^{3}$ contains 59 atoms of gold. GNR size from the protocol of our synthesis is around 15 x $50 \mathrm{~nm}[30]$. The GNR is cylindrical with hemispheric caps, yielding a volume of around $7850 \mathrm{~nm} 3$ and surface area is around $2700 \mathrm{~nm}^{2}$. From the volume, we determine that GNR have a molar weight of $9.1 \times 10^{7}$. Therefore, one GNR weighs $1.51 \times 10^{-13} \mathrm{mg}$. We have measured the yield of GNR formation after synthesis for a solution with maximum plasmon resonance of $760 \mathrm{~nm}$ and OD 2.0. The stock solution was first concentrated by centrifugation and then by evaporation in dry tubes. The total mass of GNR was found to be $47 \pm 7.37 \mathrm{mg} \mathrm{L}^{-1}$. It is important to note the theoretical maximum mass yield of GNR from our protocol is $158.6 \mathrm{mg}$ per liter of solution. After lowspeed centrifugation and removal of the pellet containing mostly platelets, stars and other non-rod-like particles (around $12 \mathrm{mg} \mathrm{L}^{-1}$ ), our yield is near 30\%. From this we conclude that our solution with OD 2.0 contains $3.11 \times$ $10^{14} \mathrm{GNR} / 1$, or a concentration of $0.52 \times 10^{-9} \mathrm{M}$ and an extinction coefficient of $3.85 \times 10^{9} \mathrm{M}-1 \mathrm{~cm}-1$. These data corroborate results from several groups $[5,27,30]$.

The zeta-potential of the GNR-CTAB complex was highly positive due to the presence of the positively charged CTAB molecules on the surface of the rods (Fig. 5). The GNR-PEG solution showed a zeta-potential which is negative and significantly different from zero. GNR surface modified with MHDA has a more negative charge than the other complexes, because MHDA has a negative carboxyl group. Both GNR conjugates (with CD33 and CD33 plus PEG) showed a zeta-potential which is slightly negative, but significantly different from zero. These results (UV VIS Spectra, and zeta-potential measures) suggested that this composition is non-precipitated complex. Zeta potential changes do confirm surface chemistry modifications, and correspond to previously published data $[6,35]$.

Statistical predictions of the number of antibodies that can attach to a nanorod aid in understanding later biochemical and optoacoustic events. Using simple geometry, we can estimate the total area of a nanorod measuring $15 \times 50 \mathrm{~nm}$ (aspect ratio of 3.5, plasmon resonance around $760 \mathrm{~nm}$ ) to about $2700 \mathrm{~nm}^{3}$. The antibody used in the following experiments, CD33, has a footprint of about 3-5 nm in radius. Assuming general bidimensional close-packing ratio of 0.8 , we can calculate we'd observe a maximum of 120-180 antibodies on one nanorod (statistical upper limit). This value has also been determined experimentally, yielding a number of CD33 per one GNR in the range of 25-40 with maximum conjugation after 12 hours and optimum concentration around 25 - $50 \mu \mathrm{g} \mathrm{mL}^{-1}$ of $1 \mathrm{nM} \mathrm{GNR}$ solutions: the molar ratio $\mathrm{mAb} / \mathrm{GNR}$ has optimum value around 500 (Fig 6).

We have compared the number of bound CD33 molecules to GNR conjugates for both described protocols. We found the previously published methods $[27,28]$ bound $30 \pm 5.5 \mathrm{mAb}$ per GNR, and we obtained $28.4 \pm 7.9$ for our modified protocol. These values are statistically identical, but our modification generates a much higher yield of conjugates, reduces the likelihood of precipitation and agglomeration of GNR conjugates, and is performed faster and at a significantly lower cost. Light microscopy visualization of CD33 receptors with silver staining for chronic (K-562) human leukemia cells has shown similar results (Fig. 7). After a $60 \mathrm{~min}$ pre-treatment with GNR conjugates obtained from both protocols described above: (activated GNR + CD33 + PEG) and (GNR + PEG and activation + CD33), we observed a similar number of dark spots which correspond to specific receptors [28].

A series of toxicology experiments was needed in order to optimize working concentration of GNR in cell suspension with minimum, or without, toxic damage. Fig. 8 presents the results for GNR-PEG administration, in different concentrations, for both acute (HL-60) and chronic leukemia (K-562) cells. We cannot observe statistically significant cell damage for concentrations lower than $1 \mathrm{nM}$, and a level of GNR-PEG lower or equal to 0.25 or $0.5 \mathrm{nM}$ has not significantly increased the number of dead cells.

We know that CTAB alone, as a quaternary ammonium surfactant, in sufficient doses can kill living mammalian cells [6]. The Siglec-3 of anti-CD33 antibody Gemtuzumab (Mylotarg ${ }^{\mathrm{TM}}$ ) is approved for treatment of acute myeloid leukemia [36]. Our experiments demonstrated similar results (Fig. 9). The number of dead cells after GNR-CTAB administration is 6-8 times higher than untreated cells, or with cell after pretreatment with GNR-PEG. We can see (Fig. 9) that after treatment of leukemia cells with CD33 alone, the number of dead HL-60 cells increases two fold (220\%), with an increase of only $150 \%$ for K-562 cells. The treatment of leukemia cells with GNR-conjugates with CD33 and PEG demonstrated the same effect: the number of dead acute leukemia cells is significant for both cell lines. It is confirmed that after conjugation, mAb CD33 retains its activity for selective binding with CD33 antigen.

Silver staining (Fig. 10) of acute (HL-60) and chronic (K-562) human leukemia cells after 60 min incubation with GNR conjugated with CD33 Antibody (GNR-CD33) has shown significantly higher number of CD33 receptors on the surface of acute leukemia cells as compared with chronic leukemia cells. It is well known that the HL-60 and K562 human myelocytic leukemia cell lines differ in their sensitivity to ether lipid anticancer drugs [3739]. These types of cells have different capabilities of transfection: high for the HL-60 and lower for the K562 cell lines [40].

The nanothermolysis has two fluence settings: low 0.6 and high $1.1 \mathrm{~J} / \mathrm{cm}^{2}$, and each setting was used for 1 and 3 pulses. From this we have 7 experimental groups of cells 


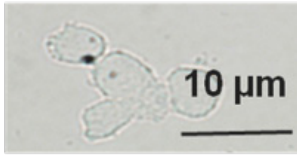

No GNR, only SS

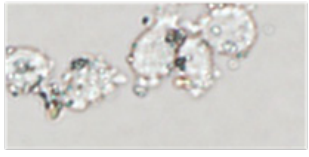

GNR-PEG

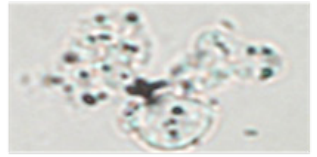

Activated GNR \&CD33 + PEG

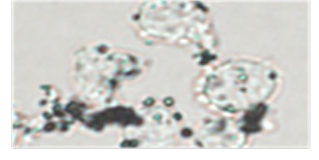

GNR+PEG \&

Activation \&CD33

Fig. 7 Silver staining of human chronic leukemia cells (K-562) after 60 min pre-treatment with pegylated (GNR-PEG), activated GNR then conjugated with CD33 monoclonal antibody and pegylated (Activated GNR + CD33 + PEG), and pegylated GNR then activated and conjugated with CD33 monoclonal antibody (GNR + PEG\&activation\&CD3

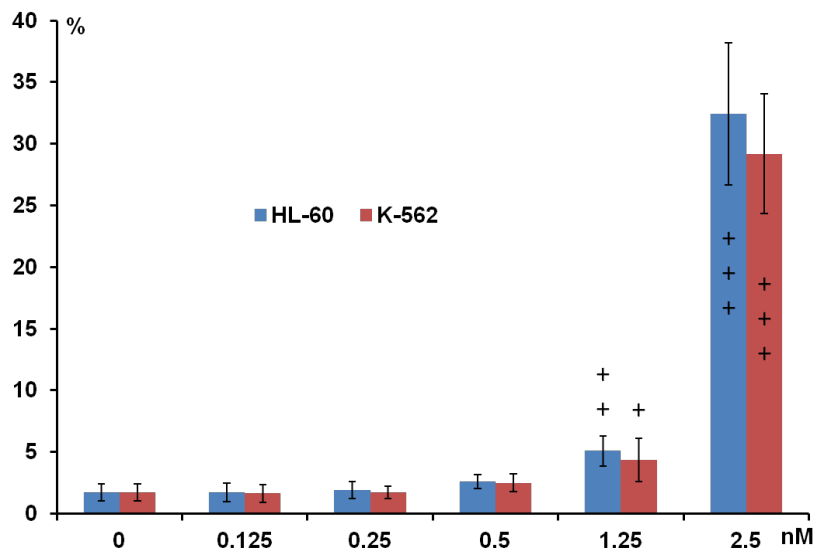

Fig. 8 Dose dependence effects on percentage of cell death for acute (H-60) and chronic (K-562) human leukemia cells after pegylated GNR administration at different concentration $(24 \mathrm{~h}, \mathrm{n}=4, \mathrm{M} \pm \mathrm{SD}),+\mathrm{P}<0.05$; $++\mathrm{P}<0.01 ;+++\mathrm{P}<0.001$ compared with control in same group cells.

(control, only laser 1 pulse, GNR-PEG 1 pulse, GNRCD33 1 pulse, only laser 3 pulses, GNR-PEG 3 pulses and GNR-CD33 3 pulses) for low and high fluence for acute (HL-60) and chronicle (K-562) human leukemia cells.

Cell viability was determined through several parameters after all treatments. The magnitude of cell death increased after laser treatment in all groups with different pulses (from 1 to 3 ), except the "only laser" group. The effect of pulsed-laser nanothermolysis for acute and chronic leukemia cells (Fig.11 and 12) demonstrated that laser application, without prior treatment with GNR, shows no measurable increase in cell counting: total number of cells, number of living cells, number of dead cells and percentage of cell death. A similar conclusion was drawn from functional viability analysis: LDH release, ratio LDH release and number of living cells, metabolic active cells (MTT assay) and ratio between LDH release and MTT parameters. However, in the "laser only" group, HL-60 cells have significantly higher damage after 3 pulses at high fluence.

Thus, the significant membrane and cell damage that occurs after laser treatment was intensified with either GNR-PEG (3 pulses for HL-60 shows significant increase but K-562 only shows a trend to increase). Pretreatment with GNR-CD33 conjugates at high laser fluence with 3 pulses demonstrated total destruction of HL-60 cells and near complete destruction for K-562.
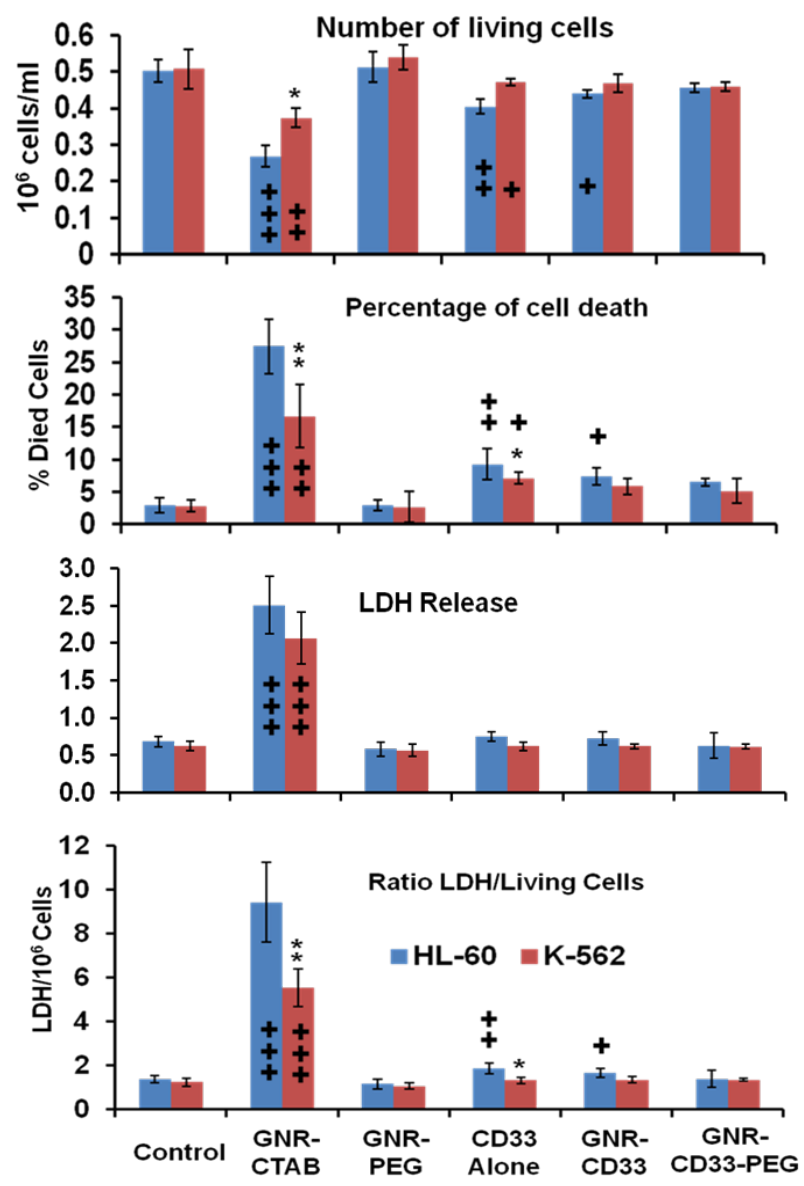

Fig. 9 Number of living cells, percentage of cell death, LDH release, ratio of LDH release to number of living cells after administration of different conjugates of GNR $(48 \mathrm{~h}, 500 \mathrm{pM}$ or $3 \times 1011 \mathrm{GNR} / \mathrm{ml}, \mathrm{n}=4$, $\mathrm{M} \pm \mathrm{SD}) .+\mathrm{P}<0.05 ;++\mathrm{P}<0.01 ;+++\mathrm{P}<0.001$ compared with control in same group of cells $* \mathrm{P}<0.05$; ** $\mathrm{P}<0.01$; *** $\mathrm{P}<0.001$ compared between acute (HL-60) and chronic (K-563) human leukemia cells at same experimental condition.

All combinations of laser treatments with pretreatment of GNR-CD33 resulted in increased cell death compared with treatment with laser alone or GNR-PEG (Fig. 11 and 12). The statistically significant differences of cell death and damage of cell membrane ( $\mathrm{LDH})$ and cell viability and proliferation (MTT assay) in the combination GNRCD33 pre-treatment and laser were observed after irradiation from 1 to 3 pulses for both laser fluence settings. These consequences were stronger for acute leukemia (HL-60) as compared with chronic leukemia (K-562) cells. 


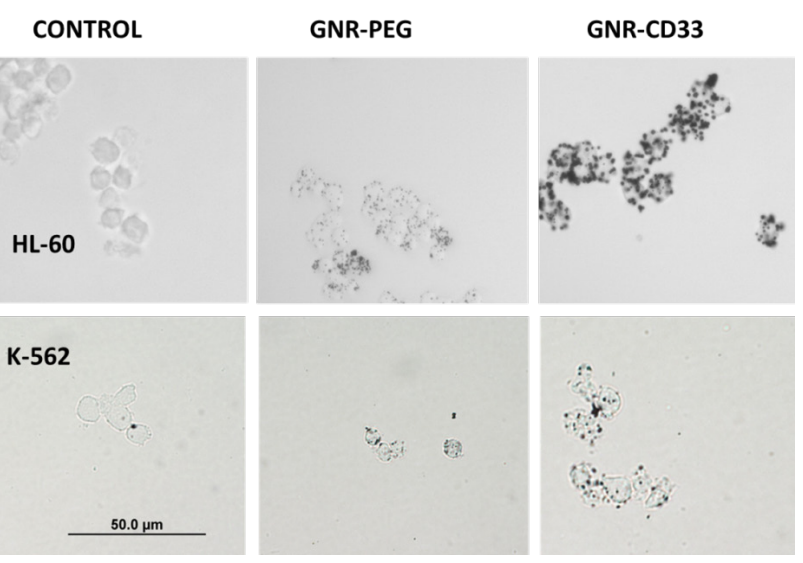

Fig. 10 Silver staining of acute (HL-60) and chronic (K-562) human leukemia cells after 60 min pre-treatment with pegylated (GNR-PEG) or conjugated with CD33 Antibody (GNR-CD33
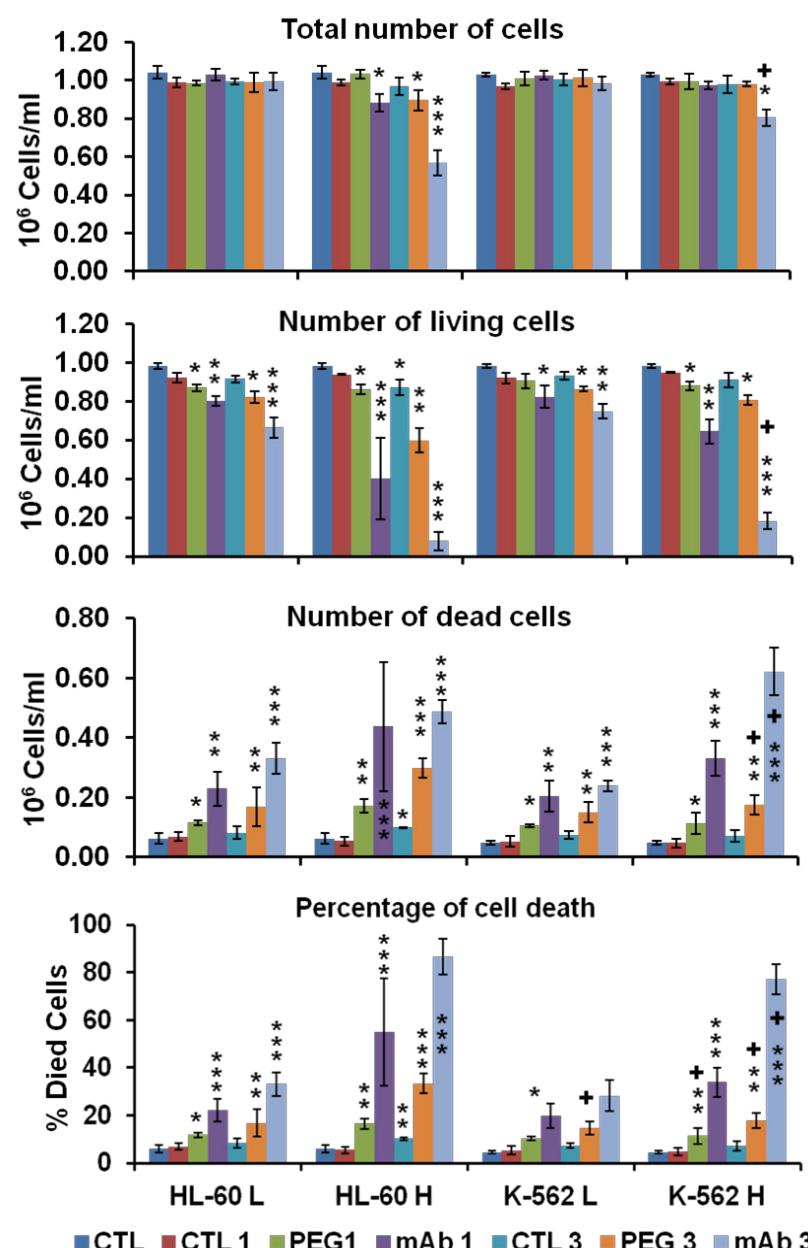

Fig. 11 Following laser administration: total number of cells, number of living cells, number of dead cells and percentage of cell death, using low $(\mathrm{L})$ and high $(\mathrm{H})$ fluence setting (with values respectively of 0.6 and 1.1 $\mathrm{J} / \mathrm{cm} 2$ ), with 1 and 3 pulses per setting (10ns, $10 \mathrm{~Hz}: \mathrm{n}=3, \mathrm{M} \pm \mathrm{SD}$ ), * $\mathrm{P}$ $<0.05 ; * * \mathrm{P}<0.01 ; * * * \mathrm{P}<0.001$ compared with control without laser, $+\mathrm{P}<0.05 ;++\mathrm{P}<0.01$; +++ $\mathrm{P}<0.001$ compared with corresponding values of the group (between HL-60 and K-562 human leukemia cells)

It is important to note that chronic leukemia cells demonstrated lower damage not only for specific binding with CD33 antigens, but also for nonspecific GNR-PEG binding. We know that both cell lines used in our report are among the most sensitive hematologic cell lines, in
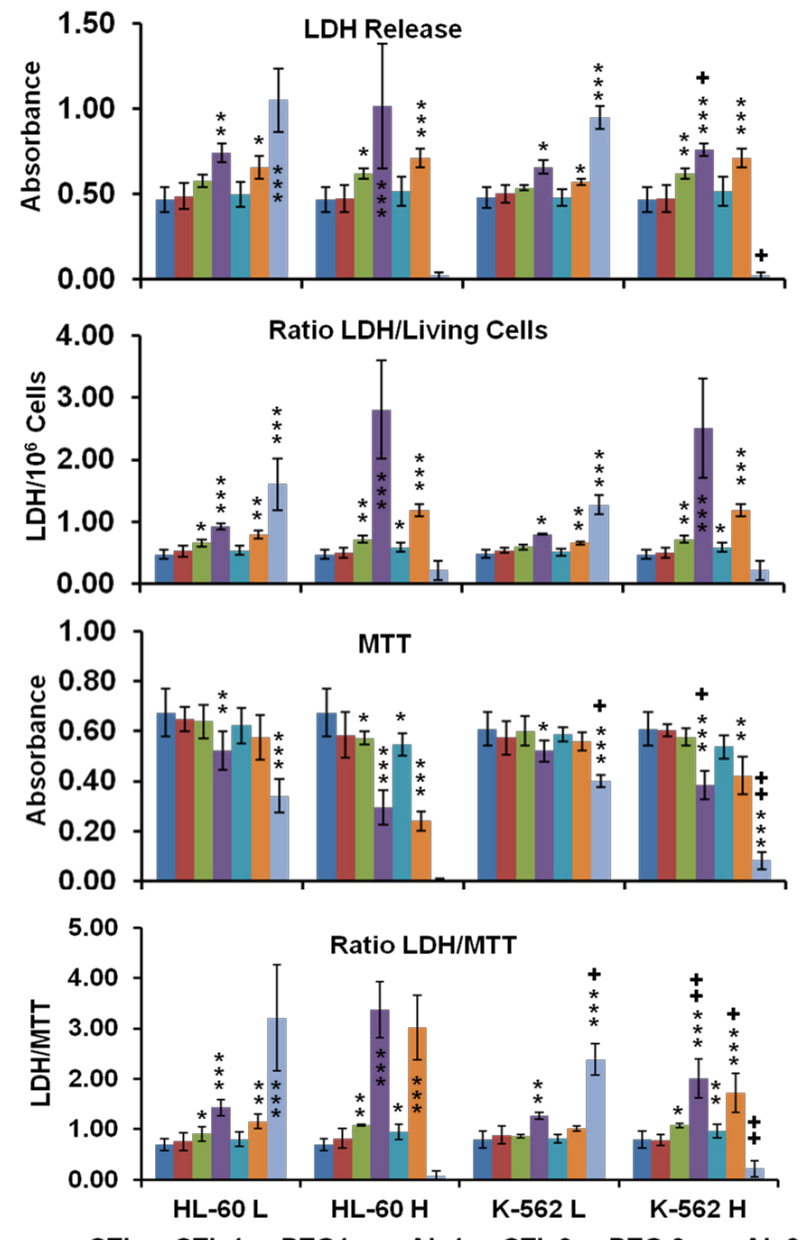

$\approx \mathrm{CTL} \approx \mathrm{CTL} 1=\mathrm{PEG} 1=\mathrm{mAb} 1 \approx \mathrm{CTL} 3 \approx \mathrm{PEG} 3 \approx \mathrm{mAb} 3$

Fig. 12 Following laser administration: $\mathrm{LDH}$ release, ratio of $\mathrm{LDH}$ release to number of living cells, metabolic active cells (MTT assay) and ratio between LDH release and MTT, all abbreviations are the same as in figure 11 .

order of decreasing sensitivity: HL-60, U937, K562, Blin-1, Nalm-6 and RPMI82 [41]. Similarly, cell count study and MTT assay in HL-60 and K562 cell lines have shown that inhibition effects of litchi chinensis leaf is higher for acute leukemia cells [42].

Our data of laser nanothermolysis has shown the level of cell death correlates with high-specificity and selective binding of GNR-CD33 conjugates with receptors on the surface of cancer cells. Similar results were published previously [23] for cells treated with gold nanoparticles and irradiated for $7 \mathrm{~min}$ with 10-ns long focused laser pulse at $532 \mathrm{~nm}$. Authors described clusterization of gold nano particles on the surface of cell membrane [23], incorporation of clusters into the cells, and destruction of the cells through bubble formation induced by laser ablation $[23,43]$. Treatment of cells with GNR-CD33 demonstrated similar results only after 1 or $310 \mathrm{~ns}$ laser pulses evidencing the much higher plasmonic absorption cross-section of GNR over gold nanoparticles [2].

As they exhibit large optical absorption cross-sections due to their surface plasmon resonance, absorbed energy 
is converted to lattice heat in pico- or several nanoseconds and heats up the nanoparticle [44, 45]. Reports in the literature have shown that cell membranes readily porate and rupture, eventually leading to cell death after pulsed laser irradiation [23, 44, 46-48]. Our data strongly confirmed that selective cell targeting, based on the use of light-absorbing GNR conjugated to mAb CD33, kills cells selectively upon exposure to short laser pulses. Such pulses ensure that the absorbed energy does not have time to diffuse away from the particles during the laser pulse and is thus confined to the small volume of the absorber [46]. To achieve thermal confinement, the pulse duration should be shorter than $1 \mathrm{~ms}$ for micrometer-sized particles, and shorter than $10 \mathrm{~ns}$ for particles smaller than $100 \mathrm{~nm}$ [46]. Additionally, heating could be accompanied by optical plasma generating shock waves with supersonic expansion and high kinetic energy, all of which can contribute to the killing of cancer cells [24, 49]. Fast bubble dynamics generate highly efficient membrane damage near the contact area [24]. Cavitation bubble patterns were shown to be generated by the photothermal nanothermolysis of cell [23]. We have shown that through binding GNR to specific cell surface antigens, therefore localizing energy deposition into the particles, selective cell damage can be achieved without affecting neighboring cells. Our findings are in correspondence with results obtained using iron oxide microspheres after single-pulse irradiation with similar laser fluence $(0.5 \mathrm{~J} /$ $\mathrm{cm}^{2}$ ), which are currently used (up to $5 \mathrm{~J} / \mathrm{cm}^{2}$ ) in clinical treatment of pigmented skin lesions[46]. GNR show optical cross-sections comparable to nanoshells, but their volume is much smaller. Therefore, gold nanorods have been widely employed as photothermal energy converters in thermolysis and many other biomedical applications [29, 44, 50-52]. The mAb-conjugated gold nanorods can be targeted to tumor cells in a site-dependent manner for maximum delivery of photoinduced injury using NIR irradiation $[49,51]$. In summary, we have established and characterized an improved protocol for conjugation and found the optimum molar ratio of $\mathrm{mAb}$ and GNR to be around 500 . We showed through viability studies performed with two types of cells that GNR-CD33 conjugates are non toxic. We have shown that GNRCD33 conjugates selectively target leukemia cells, and because of their extremely intense plasmonic resonance can destroy cancer cell in a very short time without the need to sharply focus the laser radiation. We demonstrated these findings could be successfully implemented for laser nanothermolysis of human leukemia cells using functionalized plasmonic nanoparticles.

\section{Acknowledgements}

This work was supported by the NIH (Grants R44 CA110137-05; R44 CA110137-05S1), and SBIR Grant from the National Institute of Environmental Health Sciences (1R43ES021629-01).

\section{References}

1. Perez-Juste J, Pastoria-Santos I, Liz-Marzan L M. and Mulvaney P. Gold nanorods: synthesis, characterization, and applications.
Coordination Chemistry Reviews. 2005; 249: 1870-1901. Doi: 10.1016/j.ccr.2005.01.030.

2. Oraevsky, A.,in Photoacoustic imaging and spectroscopy, Edited by L. Wang, Taylor and Francis Group, New York, 2009, chapter 30, doi: 10.1201/9781420059922.pt10.

3. Khlebstov N G. and Dykman L A. Optical properties and biomedical applications of plasmonic nanoparticles. Journal of Quantitative Spectroscopy and Radiative Transfer. 2010; 111: 1-35. Doi: 10.1016/j.jqsrt.2009.07.012.

4. Xu W, Luo T, Pang B, Li P, Zhou C, Huang P, Zhang C, Ren Q. and Shen $\mathrm{Fu} \mathrm{S}$. The radiosensitization of melanoma cells by gold nanorods irradiated with MV X-ray. Nano Biomedicine and Engineering. 2012; 4: 6-11. Doi: 10.5101/nbe.v4i1.p6-11.

5. Liao H. and Hafner J. Gold nanorod bioconjugates. Chem. Mater. 2005; 17: 4636-4641. Doi: 10.1021/cm050935k.

6. Alkilany, A. M. and Murphy, C. J. Toxicity and cellular uptake of gold nanoparticles: what we have learned so far? J Nanoparticle Research. 2010; 12: 2313-2333. Doi: 10.1007/s11051-010-9911-8.

7. Tiwari P M, Vig K, Dennis V A. and Singh S R. Functionalized gold nanoparticles and their biomedical applications. Nanomaterials. 2011; 1: 31-63. Doi: 10.3390/nano1010031.

8. Huang X, El-Sayed H, and El-Sayed M A. Applications of gold nanorods for cancer imaging and photothermal therapy. Methods in Molecular Biology. 2010; 624: 343-357. Doi: 10.1007/978-160761-609-2_23.

9. Chen S, Ji Y, Lian Q, Wen Y, Shen H, and Jia N. Gold nanorods coated with multilayer polyelectrolyte as intracellular delivery vector of antisense oligonucleotides. Nano Biomedicine and Engineering. 2010; 2: 15-23. Doi: 10.5101/nbe.v2i1.p15-23.

10. Zhang X, Pan B, Wang K, Ruan J, Bao C, Yang H, He R. and Cui D. Electrochemical property and cell toxicity of gold electrode modified by monolayer PAMAM encapsulated gold nanorods. Nano Biomedicine and Engineering, 2010; 2: 182-188. Doi: 10.5101/nbe. v2i3.p182-188

11. Dickerson E, Dreaden E, Huang X, El-Sayed H, Chu H, Pushpanketh, S., McDonald, J. and El-Sayed, M. A. Gold nanorod assisted near infrared plasmonic photothermal therapy (PPTT) of squamous cell carcinoma in mice. Cancer Lett. 2008; 269: 57-66. Doi: 10.1016/j.canlet.2008.04.026.

12. Huang X, Jain P K, El-Sayed I H, and El-Sayed M A. Plasmonic photothermal therapy (PPTT) using gold nanoparticles. Lasers Med Sci. 2007; Doi: 10.1007/s10103-007-0470-x.

13. Huang X, El-Sayed I. H, Qian W, El-Sayed M. A. Cancer cell imaging and photothermal therapy in the near-infrared region by using gold nanorods. J Am Chem Soc. 2006; 128: 2115-2120. Doi:10.1021/ja057254a.

14. Su R, Liopo A V, Brecht H P, Ermilov SA. and Oraevsky A A. Gold nanorod distribution in mouse tissues after intravenous injection monitored with optoacoustic tomography. Proceedings SPIE. 2011; 7899: 78994B. Doi: 10.1117/12.889757.

15. Conjusteau A, Liopo AV, Tsyboulski D, Ermilov SA, Elliott W R, Barsalou N, Maswadi SM, Glickman R D, and Oraevsky AA. Optoacoustic sensor for nanoparticle linked immunosorbent assay (NanoLISA). Proceedings SPIE. 2011; 7899: 789910. Doi: 10.1117/12.879401.

16. Huang H, Rege K, and Heys J. Spatiotemporal temperature distribution and cancer cell death in response to extracellular hyperthermia induced by gold nanorods. ACS Nano. 2010; 4: 28922900. Doi: $10.1021 / \mathrm{nn} 901884$ d.

17. Liao H W, Nehl C L, Hafner J H. Biomedical applications of plasmon resonant metal nanoparticles. Nanomed. 2006; 1: 201-208. Doi: 10.2217/17435889.1.2.201

18. Chamberland D L, Agarwal A, Kotov N, Fowlkes J B, Carson P L, and Wang X. Photoacoustic tomography of joints aided by an Etanercept-conjugated gold nanoparticle contrast agent -- an ex vivo preliminary rat study. Nanotechnology. 2008; 19: 095101. Doi: 10.1088/0957-4484/19/9/095101.

19. Niidome T, Yamagata M, Okamoto Y, Akiyama Y, Takahashi H, and Kawano T. PEG-modified gold nanorods with a stealth character for in vivo applications. Journal of Controlled Release. 2006; 114: 343347. Doi: 10.1016/j.jconrel.2006.06.017.

20. Roberts M J, Bentley MD. and Harris JM. Chemistry for peptide and protein PEGylation. Advanced Drug Delivery Reviews. 2002; 
54 459-476. Doi: 10.1016/S0169-409X(02)00022-4

21. Rayavarapu R G, Petersen W, Hartsuiker L, Chin P, Janssen H, Leeuwen F W B, Otto, C., Manohar, S. and Leeuwen, T. G. In vitro toxicity studies of polymer coated gold nanorods. Nanotechnology. 2010; 21: 145101. Doi: 10.1088/0957-4484/21/14/145101.

22. Urbanska K, Romanowska-Dixon B. and Matuszak Z. Indocyanine green as a prospective sensitizer for photodynamic therapy of melanomas. Acta. Biochim. Pol. 2002; 49: 387-391.

23. Lapotko D, Lukianova E, Potapnev M, Aleinikova O, and Oraevsky A. Method of laser activated nano-thermolysis for elimination of tumor cells. Cancer Lett. 2006; 239: 36-45. Doi: 10.1016/ j.canlet.2005.07.031.

24. Letfullin R, Joenathan C, George T. and Zharov V. Laser-induced explosion of gold nanoparticles: potential role for nanophotothermolysis of cancer. Nanomedicine (London), 2006; 1: 473-480. Doi: 10.2217/17435889.1.4.473.

25. Maltzahn G V, Park J H, Agrawal A, Bandaru N K, Das S K, Sailor $\mathrm{M} \mathrm{J}$, and Bhatia SN. Computationally guided photothermal tumor therapy using long-circulating gold nanorod antennas Cancer Res. 2009; 69: 3892-3900. Doi: 10.1158/0008-5472.CAN-08-4242.

26. Liopo A V, Conjusteau A, Konopleva M, Andreeff M. and Oraevsky A A. Photothermal therapy of acute leukemia cells in the nearinfrared region using gold nanorods CD-33 conjugates. Proceedings SPIE. 2011; 7897: 789710. Doi: 10.1117/12.878802.

27. Rayavarapu RG, Petersen W, Ungureanu C, Post J N, Van Leeuwen T G, and Manohar S. Synthesis and bioconjugation of gold nanoparticles as potential molecular probes for light-based imaging techniques. International Journal of biomedical imaging. 2007; 2007: 29817. Doi: 10.1155/2007/29817.

28. Eghtedari M, Liopo A V, Copland J A, Oraevsky A A. and Motamedi $\mathrm{M}$, Engineering of Hetero-Functional Gold Nanorods for the in vivo Molecular Targeting of Breast Cancer Cells. Nano Lett. 2009; 9: 287-291. Doi: 10.1021/n1802915q.

29. Green H N, Martyshkin DV, Rodenburg CM. and Rosenthal EL. Gold nanorod bioconjugates for active tumor targeting and photothermal therapy. Journal of Nanotechnology, 2011; Article ID 631753: Doi: 10.1155/2011/631753.

30. Sau TK. and Murphy C J. Seeded High Yield Synthesis of Short Au Nanorods in Aqueous Solution. Langmuir. 2004; 20: 6414-6420. Doi: $10.1021 / 1 a 049463 z$.

31. Eghtedari M, Oraevsky A A, Copland J A, Kotov N A, Conjusteau A, and Motamedi M. High sensitivity of in vivo detection of gold nanorods using a laser optoacoustic imaging system. Nano Lett. 2007; 7: 1914-1918. Doi: 10.1021/n1070557d

32. Nikoobakht B. and El-Sayed M A. Preparation and growth mechanism of gold nanorods (NRs) using seed-mediated growth method. Chemical Materials. 2003; 15: 1957-1962. Doi: 10.1021/ cm0207321.

33. Chumakova O V, Liopo A, Andreev VG, Cicenaite I, Evers B M, Chakrabarty S, Pappas TC. and Esenaliev RO. Composition of PLGA and PEI/DNA nanoparticle improves ultrasound-mediated gene delivery in solid tumor in vivo. Cancer Lett. 2008; 261: 215 225. Doi: 10.1016/j.canlet.2007.11.023.

34. Liopo A, Conjusteau A. and Oraevsky A. PEG-coated gold nanorod monoclonal antobody conjugates in preclinical research with optoacoustic tomography, photothermal therapy, and sensing. Proc. SPIE. 2012; 8223: 822344. Doi: 10.1117/12.910838.

35. Rostro-Kohanloo BC, Bickford LR, Paynem CM, Day SE,Anderson L J E, Zhong M, Lee S, Mayer KM, Zal T, Adam L, Dinney CPM, Drezek R A, West JL. and Hafner J. The stabilization and targeting of surfactant-synthesized gold nanorods. Nanotechnology. 2009; 20: 434005. Doi: 10.1088/0957-4484/20/43/434005.

36. O'Reilly MK. and Paulson JC. Siglecs as targets for therapy in immune cell mediated disease Trends Pharmacol. Sci. 2009; 30: 240-248. Doi: 10.1016/j.tips.2009.02.005

37. Tidwell T, Guzman G. and Vogler W. The effects of alkyl- lysophospholipids on leukemic cell lines I. Differential action on two leukemic cell lines, HL60 and K562. Blood. 1981; 57: 794-797.

38. Berdel, W. Ether lipids and analogs in experimental cancer therapy: A brief review of the Munich experience. Lipids, 1987; 22: 970-973.

39. Wagner B, Buettner G, Oberly L. and Burns C. Sensitivity of K562 and HL-60 cells to edelfosine, an ether lipid drug, correlates with production of reactive oxygen species. Cancer Res. 1998; 58: 2809-2816.

40. Tosi P, Pellacani A, Visani G, Ottaviani E. and Tura S. Adenovial mediated gene transfer can be accomplished inhuman myeloid cell lines and is inhibited by all-trans retinoic acid-induced differentation Haematologica. 1997; 82: 387-391.

41. Muller C, Kumagai T, O'Reilly J, Seeram N, David Heber D, and Koeffler H. Ganoderma lucidum causes apoptosis in leukemia, lymphoma, and multiple myeloma cells. Leuk. Res. 2006; 30: 841848. Doi: 10.1016/j.leukres.2005.12.004.

42. Roya S, Besraa S, Deb T, Banerjee B, Mukherjeed J, and Vedasiromoni J, Induction of apoptosis in human leukemic cell lines U937, K562 and HL-60 by litchi chinensis leaf extract via activation of mitochondria mediated caspase cascades. The Open Leukemia Journal. 2008; 1: 1-14. Doi:10.2174/1876816400 901010001.

43. Hleb EY, Hafner JH, Myers JN, Hanna EY, Rostro BC, Zhdanok S A, and Lapotko DO. LANTCET: elimination of solid tumor cells with photothermal bubbles generated around clusters of gold nanoparticles. Nanomed. 2008; 3: 647-667. Doi: 10.2217/17435889.3.5.647.

44. Lukianova-Hleb, E. Y, Hanna E. Y, Hafner J, and Lapotko D Tunable plasmonic nanobubbles for cell theranostics. Nanotechnology. 2010; 21: 85102. Doi: 10.1088/09574484/21/8/085102.

45. Wu TH, Teslaa T, Teitell MA. and Chiou PY. Photothermal nanoblade for patterned cell membrane cutting. Opt Express. 2010; 18: 23153. Doi: 10.1364/OE.18.023153.

46. Pistillides CM, Joe EK, Wei XB, Anderson RR. and Lin CP. Selective cell targeting with light-absorbing microparticles and nanoparticles. Biophys J. 2003; 84: 4023.

47. Wang S, Chen KJ, Wu TH, Wang H, Lin WY, Ohashi M, Chiou PY, and Tseng HR. Photothermal effects of supramolecularly assembled gold nanoparticles for the targeted treatment of cancer cells. Angew Chem Int Ed Engl. 2010; 49: 3777. Doi: 10.1002/ anie. 201000062.

48. Wu TH, Kalim S, Callahan C, Teitell MA. and Chiou PY. Image patterned molecular delivery into live cells using gold particle coated substrates. Opt Express. 2010; 18: 938. Doi: 10.1364/ OE.18.000938

49. Tong L, Zhao Y, Huff TB, Hansen MN, Wei A. and Cheng JX. Gold nanorods mediated tumor cell death by compromising membrane integrity. Advanced Materials. 2007; 19: 3136. Doi: 10.1002/adma.200701974

50. Tong L, Wei Q, Wei A. and Cheng JX. Gold nanorods as contrast agents for biological imaging: optical properties, surface conjugation and photothermal effects. Photochem Photobiol. 2009; 85: 21-32. Doi: 10.1111/j.1751-1097.2008.00507.x.

51. Stone J, Jackson S. and Wright D. Biological applications of gold nanorods. Wiley Interdisciplinary Rev: Nanomedicine Nanobiotechnology. 2010; 3: 100. Doi: 10.1002/wnan.120.

52. Bartczak D, Muskens OL, Millar TM, Sanchez-Elsner T. and Kanaras AG. Laser-induced damage and recovery of plasmonically targeted human endothelial cells. Nano Lett. 2011; 11: 1358. Doi: $10.1021 / \mathrm{nl} 104528 \mathrm{~s}$.

Copyright:(c) 2012 Anton V. Liopo. et al. This is an openaccess article distributed under the terms of the Creative Commons Attribution License, which permits unrestricted use, distribution, and reproduction in any medium, provided the original author and source are credited. 